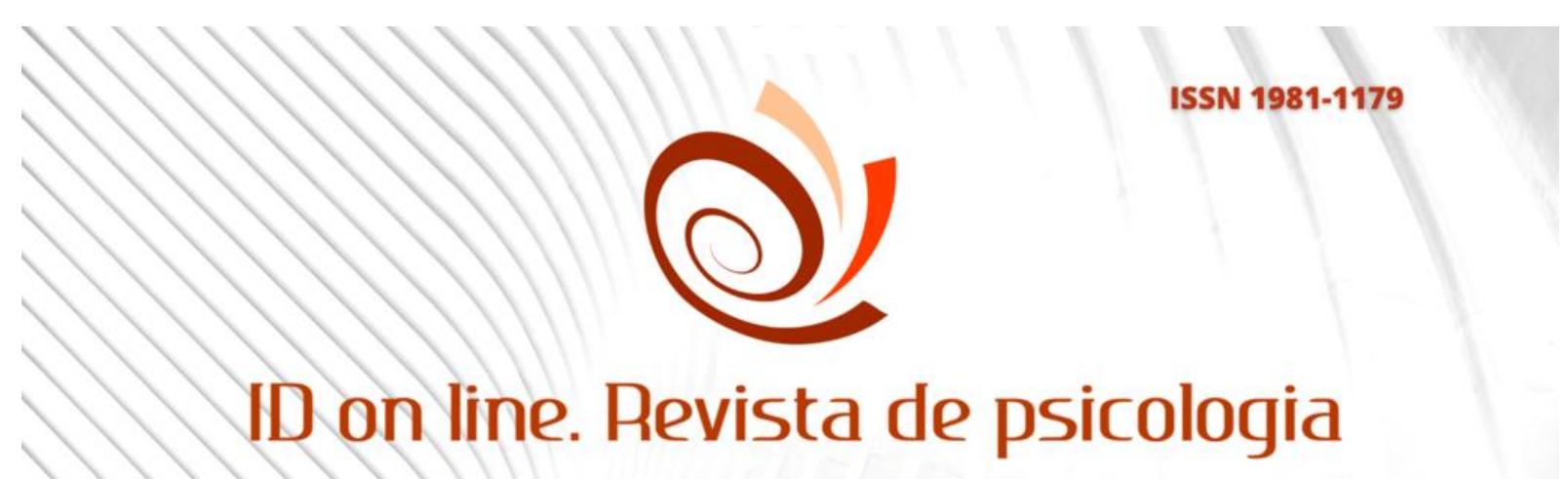

लाखो

DOI: 10.14295/idonline.v15i57.3248

Comment

\title{
A Relevância da Família no Processo Educacional: Perspectivas e Desafios Segundo o Projeto Político Pedagógico da Escola Cleuzemi Pereira do Nascimento Silva
}

\author{
Yara Silva da Costa ${ }^{l}$; Marluce Iraneide da Silva ${ }^{2}$; Pedro Fernando dos Santos ${ }^{3}$;
}

\begin{abstract}
Resumo: Esse trabalho tem por finalidade demostrar e analisar a importância da família no processo de aprendizagem do aluno, sendo assim, um dos principais motivos a serem alcançados é trazer a instituição família para esse ambiente escolar. O objetivo deste trabalho é compreender a construção do Projeto Político Pedagógico (PPP) em uma Gestão Democrática e Participativa. Visando ainda, destacar as práticas, valores e rotinas enfatizados no cotidiano escolar visando a realidade local que repercutem no espaço familiar. $\mathrm{O}$ estudo tem como base refletir a participação coletiva na construção do Projeto Político Pedagógico, entendido como a própria organização do trabalho pedagógico da escola como um todo. O trabalho desenvolvido é de natureza qualitativa com adição do campo, que se deu dentro das atividades do Programa de Residência Pedagógica, Além de adotar para a sua realização, teorias como as de Veiga (1994), Garcêz (2012), Polonia e Dessen (2005), Garcia (2006), a Lei de Diretrizes e Bases da Educação Nacional (LDBEN 9394/96) e leitura de artigos. Diante disso, foi possível compreender a importâncias da relação entre Família e Escola não somente na construção do PPP, mas também com alicerce na formação de cidadãos como meio de transformação no meio educacional.
\end{abstract}

Palavras-Chave: Família; Escola; Relação; Aprendizagem; PPP.

\section{The Relevance of the Family in the Educational Process: Perspectives and Challenges According to the Political Pedagogical Project of the Cleuzemi Pereira do Nascimento Silva School}

\footnotetext{
Abstract: This work aims to demonstrate and analyze the importance of the family in the student's learning process, thus, one of the main reasons to be achieved is to bring the family institution to this school environment. The objective of this work is to understand the construction of the Pedagogical Political Project (PPP) in a Democratic and Participatory Management. Also aiming to highlight the practices, values and routines emphasized in the daily school life, aiming at the local reality that affect the family space. The study is based on

${ }^{1}$ Graduanda em Pedagogia. Faculdade de Ciências Humanas do Sertão Central (FACHUSC), Brasil. yarakoosta@gmail.com;

${ }^{2}$ Graduanda em Pedagogia. Faculdade de Ciências Humanas do Sertão Central (FACHUSC), Brasil. marluce.silva@fachusc.com;

${ }^{3}$ Mestrado em Educação pela Universidade do Estado do Rio Grande do Norte-RN. Professor na Faculdade Ciências Humanas do Sertão Central (FACHUSC). Brasil. pedrinho_quilombola@hotmail.com.
} 
reflecting the collective participation in the construction of the Political Pedagogical Project, understood as the organization of the school's pedagogical work as a whole. The work developed is of a qualitative nature with the addition of the field, which took place within the activities of the Pedagogical Residency Program, in addition to adopting theories such as those of Veiga (1994), Garcêz (2012), Polonia and Dessen (2005), Garcia (2006), the Law of Guidelines and Bases of National Education (LDBEN 9394/96) and reading of articles. Therefore, it was possible to understand the importance of the relationship between Family and School not only in the construction of the PPP, but also based on the formation of citizens as a means of transformation in the educational environment.

Keywords: Family; School; Relationship; Learning; PPP.

\section{Introdução}

O trabalho tem por objetivo compreender a criação do Projeto Político Pedagógico (PPP) em uma Gestão Democrática e Participativa. ainda destacar as práticas, valores e rotinas enfatizados no cotidiano escolar, visando a realidade local que refletem no espaço familiar e encadeiam aos valores, práticas e rotinas familiares na construção de disposições permanentes, favoráveis ao aprendizado escolar diante dos pontos importantes numa elaboração coletiva do PPP, consistindo um documento que trata dos objetivos, metas e ações para serem desenvolvidos no âmbito educacional de acordo com a realidade local da escola e relatar a relevância da parceria Família e Escola no processo de construção do Projeto Político Pedagógico.

O estudo tem como base refletir a participação coletiva na construção do PPP, compreendido como respectiva organização do trabalho pedagógico da escola em sua totalidade. A função educativa da família é indispensável no processo de aprendizagem do aluno. O círculo familiar é o primeiro contato social da criança, tratando-se de grande importância em sua educação, visto que é nesse ambiente familiar que a criança aprenderá valores sociais, éticos e culturais, e também, terá amparo e capacitação para um desenvolvimento saudável.

Nessa perspectiva, o PPP é um documento que tem como proposito principal o planejamento e o acompanhamento das atividades em um ambiente escolar, que reflete a proposta educativa do estabelecimento de ensino. É um documento que deve ser criado por todas as escolas onde enuncia Lei de Diretrizes e Bases da Educação Nacional (LDBEN 9394/96) no Art. 12 inciso 1 (BRASIL,1996) “Os estabelecimentos de ensino, respeitadas as normas comuns e as do seu sistema de ensino, terão a incumbência de: I - laborar e executar sua proposta pedagógica". 
Sendo assim, torna-se indispensável abordar a participação da família correspondente as convicções pedagógicas da gestão democrática e participativa na construção do PPP, a partir de tomadas de decisões em conjunto. Podendo trazer muitos benefícios à escola aos discentes, assegurando um exercício educativo que de fato estabeleça uma aprendizagem e originando bons resultados na formação dos indivíduos, tornados sujeitos críticos e reflexivos.

\title{
Sociedade, Política e Educação
}

Tendo em vista que "Para compreendemos o sentido da escola, sua função social e a natureza do trabalho educativo, precisamos antes entender em que tipo de sociedade estamos inseridos.” (Projeto Político Pedagógico, p. 27) Sendo assim, precisamos compreender a realidade onde a instituição de ensino está inserida para entendermos e analisarmos o seu PPP.

\begin{abstract}
"Se pensamos que a comunidade possui uma parcela de pais analfabetos e de pais com Ensino Fundamental incompleto fica clara a carência ligada à educação e ao tipo de acesso e trato à informação que ela gera, o que impossibilita e/ou inibe a participação social. Percebe-se que esse fator dificulta o auxílio da família nas atividades do "para casa" e no incentivo à frequência escolar." (Projeto Político Pedagógico, p.15)
\end{abstract}

Quando se fala em acesso à educação falamos de um direito consolidado por lei. Conquanto, como na maior parte do país esse direito é negligenciado, um estigma social que, por falta de políticas públicas efetivas que garantam esse acesso e permanência na escola, continua afetando a sociedade em seus núcleos mais carentes. Sendo assim, no município de Salgueiro Pernambuco não seria diferente.

De acordo com a Pesquisa Nacional por Amostra de Domicílios Contínua (PNAD) (IBGE, 2013. p. 32) “96,7\% das crianças matriculadas em 2013 em instituições de ensino em Salgueiro-PE, apenas 50,4\% concluíram o Ensino Fundamental na idade adequada, evidenciando assim o problema que o município enfrenta na formação dos alunos e em manter os alunos na escola". A construção de PPP que abranja adequadamente todos os aspetos sociais que os estudantes fazem parte é de fundamental importância para a garantia de uma educação de qualidade.

Segundo VEIGA (1994, p. 579);

\footnotetext{
"Todo projeto supõe rupturas com o presente e promessas para o futuro. Projetar significa tentar quebrar um estado confortável para arriscar-se, atravessar um período de instabilidade e buscar uma nova estabilidade em função da promessa que cada projeto contém de estado melhor do que o presente."
} 
O PPP é um mecanismo de desenvolvimento social atuando na formação de cidadãos críticos e conscientes. E ainda, "O direito à educação de qualidade é, antes de tudo, um direito humano fundamental que permite a participação efetiva de todos nas sociedades contemporâneas [...]" (Lei Municipal n 1.946/2015. p.14) possibilitando a construção de uma sociedade mais justa e democrática.

\section{A Parceria Família e Escola: Inseridos na Construção do Projeto Político Pedagógico}

A Escola Cleuzemi Pereira do Nascimento Silva estimula a participação da família no âmbito escolar através de atividades educativas e sociais, como voluntariado com o desenvolvimento de projetos que promovem encontros e visitas, a fim de compartilhar, alegrias e conhecimentos.

Tendo em vista o momento pandêmico em que vivemos a escola não vem recebendo de maneira assídua a visita dos familiares, no entanto há em vigência o concurso LER BEM onde os familiares dos educandos visitaram a escola para acompanhar o desenvolvimento do referido concurso junto à comunidade escolar.

Diante disso, a instituição promoveu o Projeto Sacola Viajante com propósito de incentivar e despertar o gosto pela leitura e aproximar a família da escola, principalmente em tempos de pandemia, sendo que os discentes têm acompanhamento online junto aos docentes, tendo os pais como mediadores de ensino, o projeto atende ao público do Ensino Fundamental anos iniciais do $1^{\circ}$ ao $5^{\circ}$ ano e auxílio na biblioteca, projeto sacola viajante.

É de grande importância a leitura para o desenvolvimento da alfabetização e do letramento, o projeto vem para somar onde o estudante, pais ou responsáveis devem se deslocar até a escola duas vezes por semana na segunda-feira e na quarta-feira para pegar a sacola e um paradidático assinando o caderno de controle e o livro deve ser lido em casa com a família de acordo com a faixa etária do estudante, ou seja, a sua idade e seu ano de escolaridade, onde haverá o acompanhamento da evolução da leitura do aluno através de vidio aula, para posterior devolução do livro, da leitura como afirma no os PCN's (BRASIL, 1997, p.38):

\footnotetext{
"Formar um leitor competente supõe formar alguém que compreenda o que lê que possa aprender a ler também o que não está escrito, identificando elementos implícitos, que estabeleça relações entre o texto que lê e outros textos já lidos; que saiba que vários sentidos podem ser atribuídos a um texto, que consiga justificar e validar a sua leitura a partir da localização de elementos discursivos"
} 
Tendo em vista que a realização dessas atividades é de suma importância para o desenvolvimento. Contudo, a instituição deve promover estratégias e vivencias dos quais a família venha participar junto com os discentes na formação de leitores criando possibilidades de leitura de fatos explícitos de várias formas de interpretação. Proporcionando assim um mundo mágico onde o aluno irá descobrir e se tornar um cidadão crítico diante de suas opiniões onde se abre um leque de oportunidades de crescimento para este educando. Para isso é importante estabelecer uma proximidade família-escola com a escola.

De acordo com o PPP:

\begin{abstract}
“A parceria família escola, baseada na cooperação, no respeito e na confiança, é imprescindível para o sucesso da educação de nossos estudantes, uma vez que há objetivos comuns como a formação de valores morais, a construção de conhecimentos e, a autorrealização de cada um deles.” (PPP - Projeto Político Pedagógico, 2019, p. 45)
\end{abstract}

Desta forma, o acompanhamento e a participação da família na realização das atividades são de grande importância para a vida escolar das crianças, mesmo diante do cenário vivido por conta da pandemia acometido no mundo, a escola busca de todas as formas ajustar a parceria com a família.

Pode-se constatar que o PPP aborda propostas de ações concretas para executar o debate e a participação por conceituar a escola com um ambiente de formação de cidadãos conscientes, responsáveis e críticos. Define e organiza atividades educativas necessárias ao exercício do ensino-aprendizagem incorporando a atuação da família. Portanto o documento norteador da escola precisa contemplar a narrativa com o núcleo familiar, recursos, na construção do conjunto de orientações pedagógicas e plano de ação.

O PPP deve ser analisado regularmente para que garanta suas ações e objetivos. A atividade educacional é de caráter indispensável na construção efetiva do ser humano ao decorrer de todo o exercício pedagógico é necessário compreender o que se modificou e o que necessita mudar.

Perante as restrições globais provocadas pelo novo coronavírus, o fechamento das escolas se tornou uma obrigação, mudando assim a rotina e de todos os profissionais da educação, onde foi preciso uma readequação no ensino em si, havendo a necessidade de adequação aos meios tecnológicos, tanto de discentes e docentes para a realização das aulas remotamente. 
O PPP é um documento flexível que pode sofrer mudanças, diante de qualquer circunstância em decorrência dos fatos, mediante a qualidade do ensino-aprendizagem. $\mathrm{O}$ plano de ação precisa ser analisado e adequado com a situação. Ocorrendo a solicitação de todos os envolvidos, professores, gestores, funcionários, coordenadores, pais e comunidade para construção do plano de contingência para organizar, orientar, e dar as respostas necessárias para intervir, controlar e combater as consequências do impacto, proporcionando práticas para um retorno seguro as aulas presenciais.

No entanto, os profissionais da educação, os docentes estão se qualificando a cada dia para que tragam o desenvolvimento integral dos estudantes no processo ensino/aprendizagem. Notabiliza-se que esse processo de qualificação é de grande importância para a comunidade escolar em geral, com isso precisa ser analisado, compreendido e explorado, para que assim se tenha a noção como se anda a estrutura da escola, como também a parte pedagógica, visando a melhor educação e aprendizagem dos alunos.

\section{As Contribuições da Família na Escola}

O agrupamento família, exerce a função de efetuar a formação do indivíduo, em rezão de serem os responsáveis diretos, entretanto a função de educar, de fornecer a educação formal é responsabilidade da escola, ambos são corresponsáveis pela formação cognitiva, afetiva, social e da personalidade das crianças e adolescentes. Assim como diz (GARCÊZ, 2012) "Embora família e escola sejam duas instituições diferenciadas, mas com o mesmo objetivo a cumprir, fazer com que a criança se desenvolva positivamente em todos os seus aspectos $[\ldots] "$.

Sabemos que a família é o primeiro meio social que a criança tem contato, depois vem a escola e, dessa forma as duas as instituições devem ter uma relação de confiança, pois é isso que a criança precisa para melhorar seu processo de aprendizagem. A relação entre família e escola auxilia com o ambiente de aprendizado, porque essa relação estabelece uma boa convivência, dialogando e compartilhando conhecimento.

A instituição família é o grupo que permeia as vivências da criança e tem como obrigação moral, social e humana fortalecer nela uma educação que possa ir preparando o caráter para futuramente adquirir/desenvolver comportamentos mais proveitosos $\mathrm{e}$ satisfatórias para a sociedade e também relacionado a sua aprendizagem escolar. 
A instrução escolar da criança está diretamente relacionada à participação familiar na escola. A instituição familiar é fundamental no crescimento da criança, jovens e adultos, com isso a mesma tem que estar a par da situação de seus filhos. Criando o laço com a escola, nas tomadas de decisões cabíveis, mediante as normas internas e externas da escola.

A cooperação dos pais/responsáveis no ambiente escolar se faz necessária sempre. Qualquer criança, no momento que começa a crescer, passa a agir de jeito mais autônomo e, a família precisa se entender de que não é suficiente apenas ser os pais, mas que ela deve participar da vida de seu filho. Pois o sucesso no processo educacional também está ligado ao envolvimento da família em conjunto com a escola. A mesma tem na instituição escolar, como o eixo de assistência, em consequência de que a mulher deixar de ser só dona de casa e se tornou a dona do lar em várias áreas da família.

Dentre as atividades propostas no PPP da Escola Cleuzemir Pereira do Nascimento para ligar a família a escola podemos destacar o Projeto Sacola Viajante que tem como objetivo ressaltar a importância da leitura, buscando meios de aproximar mais a escola e a família em tempos de pandemia, além de envolver o engajamento maior entre alunos, família e escola.

Sendo assim, tal projeto visa ampliar as contribuições da família na escola para que assim busque a otimização entre ambas as instituições com o objetivo de melhorar o aprendizado do educando. Assim como afirma; (POLONIA E DESSEN, 2005, p. 304)

\footnotetext{
“A escola deve reconhecer a importância da colaboração dos Pais na história e no projeto escolar dos alunos e auxiliar as famílias a exercerem o seu papel na educação, na evolução e no sucesso profissional dos filhos e, concomitantemente, na transformação da sociedade"
}

O Projeto Político Pedagógico da referida escola campo contempla e valoriza a inserção e a participação da família na escola para que de forma objetiva contribuam para o desenvolvimento pleno das crianças e o bom funcionamento da escola.

A escola deve continuar o processo educativo que vem da família, introduzindo a formação acadêmica que é necessária para a construção intelectual e profissional do indivíduo, por isso, juntas devem fortalecer a formação de valores, favorecendo os educandos.

Segundo (GARCIA, 2006, p. 12);

A parceria entre família e a escola é de suma importância para o sucesso no desenvolvimento intelectual, moral e na formação do indivíduo na faixa etária escolar. [...] afinal, por que até hoje em pleno século XXI a escola reclama da pouca ou insignificante participação da família na escola, na vida escolar de seus 
filhos? Seria uma confusão de papéis? Onde estaria escondido o ponto central desse dilema que se arrastam por anos e anos?

Escola e família desempenham papéis decisivos na formação e na educação da criança. Os pais acreditam que a continuação do lar é a escola e esperam dela o que na sua essência é de sua responsabilidade. A escola por sua vez, também costuma depositar toda a responsabilidade de iniciativa assomada a família. A pandemia reforça a imprescindível e essencial participação da família no acompanhamento da vida escolar dos filhos, principalmente porque, agora, a educação de forma efetiva está dentro de suas residências. O pai, mãe ou responsável são capazes de avaliar quais são as atividades desenvolvidas e, por isso o envolvimento familiar tornou-se mais intensivo.

A dúvida de papéis ligados entre família e escola sempre aconteceu e que foi dada a escola a função de preocupar-se com a segurança, alimentação e as precauções básicos entorno das crianças, no entanto durante a pandemia a escola não conseguiu manter e cuidar da aprendizagem que é a principal de sua missão. Por esta razão se faz necessário a participação ativa da família nos encontros coletivos, mesmo que virtuais e em finalização de projetos haja vista as vantagens desse vínculo e acolhimento.

Diante da pandemia, mesmo com um número limitado as famílias e responsáveis estão esforçando-se o tempo e investindo de recursos para ajudar na aprendizagem dos filhos, de certa forma há uma contribuição na construção do saber das crianças mesmo com o enfrentamento de desafios imprevisíveis.

\section{Metodologia}

A pesquisa desenvolvida é de natureza qualitativa com foco no processo de ensino e aprendizagem e se as ações descritas no Projeto Político Pedagógico estão condizentes com a prática cotidiana.

Este artigo tem como metodologia o estudo através de observações no campo de estudo, embasamento no PPP, documento norteado da escola onde foi realizada a pesquisa, Escola Professora Cleuzemi Pereira do Nascimento Silva e, artigos para posterior análise da intrínseca relação entre família e escola. Tendo como base este documento citado e leitura de artigos de igual natureza, bem como renomados autores foi possível constatar a importância dessa relação para o bom funcionamento da escola. 
Além disso, compreende-se que a escola precisa ter apoio da família na tomada de decisões, bem como a família necessita da escola para modificações necessárias para a sociedade. E mesmo que diante da pandemia é preciso ações que aproximem essas instituições. Para desenvolver a pesquisa foi preciso ser feito a leitura de artigos para ter mais conhecimentos, como embasamentos analisando criteriosamente o projeto político pedagógico da escola, de modo que várias teorias utilizadas, se tornaram indispensáveis para esta análise.

\section{Resultados e Discussões}

É oportuno enfatizar que a parceria entre Família e Escola é um dos maiores elementos capazes de levar a educação ao sucesso esperado. Acredita-se que ambos precisam estar em constante sintonia, pois a educação é responsabilidade de todos, pois estão envolvidos no desenvolvimento dos discentes. Sendo assim, "O principal objetivo é preparar o estudante para a vida por meio do conhecimento, orientando-o para uma educação continuada, permanente, com os demais agentes educativos, principalmente a família, que o apoiará no exercício da cidadania e nas escolhas profissionais.” (Projeto Político Pedagógico, p. 16)

Compreende-se então, que a família desempenha o papel de alicerce na formação das crianças e jovens tendo em vista que é a primeira instituição social que os envolve (LDB, 1996). Portanto, na construção do PPP a família é um elemento fundamental que se deve analisar. Ainda, segundo o Projeto Político Pedagógico "a educação considera a interação de todos os aspectos da pessoa humana com a sociedade na qual está inserida [...]" (Projeto Político Pedagógico, p. 29) e ainda traz dois questionamentos que se precisa ponderar "[...]Que tipo de homem desejamos obter com o produto do nosso trabalho? - Que tipo de sociedade interage com este homem que pretendemos formar?" (Projeto Político Pedagógico, p. 29).

Essas são algumas das questões levadas em consideração para obter um Projeto Político-Pedagógico eficaz e, que agregue à sociedade. Além disso, o PPP da escola objeto de análise tem como missão;

\footnotetext{
"Preparar o estudante para os desafios da vida, gerando uma aprendizagem afetiva e levando-o a distinguir valores que edificam o homem e a sociedade, daqueles que privilegiam o individualismo e a competição desigual, garantindo ao estudante o acesso e a permanência à escola, formando cidadãos críticos, reflexivos e conscientes para os desafios da sociedade." (Projeto Político Pedagógico, p.29)
} 
Diante disso, espera-se que o Projeto Político Pedagógico se adeque a nova realidade, cujo objetivo é uma escola que responda a demanda com a melhoria na qualidade do ensino. As observações obtidas dentro da escola vão bem mais adiante do que apenas estrutura física, é conhecer cada detalhe, saber como a escola e a família devem ser parcerias para um bom desempenho dos papéis decisivo na educação dos alunos. Tendo em vista, a obrigatoriedade do afastamento social impondo à necessidade de aulas remotas, nota-se a baixa dessa relação, onde família e escola tiveram a maioria dos encontros de forma remota e, que existe essa necessidade de estreitar este vínculo para o melhor rendimento dos alunos e funcionamento da escola.

\section{Considerações Finais}

Ao elaborar esse estudo notamos que o Projeto Político Pedagógico é um documento bastante valioso e essencial já visto, traduz a identidade da escola além de definir as diretrizes e objetivos da instituição de ensino, para que a qualidade de ensino melhore cada vez mais. Percebe-se que a escola campo onde foi realizada a pesquisa preocupa-se em construir e executar esse documento com bastante coerência e responsabilidade, com a colaboração da direção, pais, alunos e toda comunidade escolar.

Decorrente da situação de pandemia do nova corona vírus, a gestão escolar se deparou com muitos problemas, sendo necessário fazer diversas alterações, pois não é fácil manter os alunos escutando, realizando as atividades ou até mesmo compreendendo e aprendendo, pois os educadores enfrentam muitas dificuldades, por seus alunos pertencerem na grande maioria, a classe baixa, sem condições de usar os meios de tecnologias, para acessar as aulas realizadas de forma remota.

Em conversa com as diretoras e a secretária vimos a secretaria que a escola Cleuzemir Pereira, tem uma prática educativa inovadora, portanto, o Projeto Político Pedagógico é bastante dinâmico e está sempre em constante transformação, esse momento de conhecimento é riquíssimo, onde cada um dos envolvidos aprende ensinando. Essa conscientização é necessária para enriquecer o desenvolvimento do trabalho e consequentemente seus respetivos resultados. 
É notório que, tanto a gestão como os demais membros da escola, têm total conhecimento sobre Projeto Político Pedagógico, pois demonstraram clara sua atenção e dedicação na elaboração, cujo objetivo é a melhoria do ambiente escolar, da forma de ensino e formar esse sujeito social, alcançando assim a referência social almeida, que é uma boa qualidade do ensino e resultado cada vez mais satisfatórios.

\section{Referências}

BRASIL, Lei 9394/96, 20 dez. 1996. Estabelece as diretrizes e bases da educação nacional. Diário Oficial da República Federativa do Brasil, DE, 31. dez. 1996.

BRASIL. Ministério da Educação e do Desporto. Secretaria de Educação Fundamental. Parâmetros curriculares nacionais ( $1^{a}$ a $4^{\text {a }}$ séries): língua portuguesa, vol. 02. Brasília, 1997. Disponível em: <http://portal.mec.gov.br/seb/arquivos/pdf/livro02.pdf\&gt; Acesso em: 20 set. 2021.

GOLDENBERG, Mirian. A arte de pesquisar: como fazer pesquisa qualitativa em Ciências Sociais. $10^{\circ}$ Ed. Rio de Janeiro: Record,2007

PME, PLANO MUNICIPAL DE EDUCAÇÃO DE SALGUEIRO. Salgueiro, Pernambuco 23/06/2015. Lei Municipal no. 1.949/2015. p. 76.

PROJETO POLÍTICO-PEDAGÓGICO DA ESCOLA. Salgueiro, 2020. p. 70.

PROJETO POLÍTICO PEDAGÓGICO. Colégio Estadual Padre Chagas - EFM, 2014.

PROJETO POLÍTICO PEDAGÓGICO. do Colégio Estadual do Campo da Palmeirinha EFM, 2014.

SILVA, Maria Abadia da. Do projeto político do Banco Mundial: ao projeto político pedagógico da escola pública brasileira. In: Arte \& Manhas dos Projetos Políticos e Pedagógicos. Campinas SP: CEDES, 2003, v23/n.61

SILVA, Maria de Lourdes Garcêz da; CAVALCANTE, Luciana Matias. Relação família/escola: as contribuições da família no processo pedagógico vivido na educação infantil. foro internacional de pedagogia, v. 4, p. 1-12, 2012.

VEIGA, L.P. Projeto Político Pedagógico da Escola: uma construção possível. Campinas Papirus, / 1995.p.11-36.

\section{Como citar este artigo (Formato ABNT):}

COSTA, Yara Silva da; SANTOS, SILVA, marluce Iraneide; Pedro Fernando dos. A Relevância da Família no Processo Educacional: Perspectivas e Desafios segundo o Projeto Político Pedagógico da Escola Cleuzemi Pereira do Nascimento Silva. Id on Line Rev. Psic., Outubro/2021, vol.15, n.57, p. 729-739, ISSN: 1981-1179.

Recebido: 08/10/2021;

Aceito 25/10/2021;

Publicado em: 31/10/2021. 